\title{
Article \\ Effect of Aging Time on Crushing Performance of Al-0.5Mg-0.4Si Alloy for Safety Components of Automobile
}

\author{
Jinkun Lu ${ }^{1}$, Haichun Jiang ${ }^{2,3, *}$, Lingying Ye ${ }^{1}\left(\mathbb{D}\right.$, Daxiang Sun ${ }^{4}$, Yong Zhang ${ }^{1}$, Xin Zhan ${ }^{1}$, Yuping Li ${ }^{1}$, \\ Lehang Ma ${ }^{1}$, Qingrong Ran $^{3}$ and Jianguo Tang ${ }^{1,5, *}$ \\ 1 School of Materials Science and Engineering, Central South University, Changsha 410083, China; \\ loojkccc@csu.edu.cn (J.L.); lingyingye@csu.edu.cn (L.Y.); yong.zhang@csu.edu.cn (Y.Z.); \\ labronchan@csu.edu.cn (X.Z.); yupingli@csu.edu.cn (Y.L.); 173812047@csu.edu.cn (L.M.) \\ 2 Zhejiang Minneng Technology Co., Ltd., Huzhou 313300, China \\ 3 MINTH Research and Development Center, Ningbo 315800, China; qingrong.ran@minthgroup.com \\ 4 Center for Industrial Analysis and Testing, Guangdong Academy of Sciences, Guangzhou 510650, China; \\ eagle19840831@sina.com \\ 5 Light Alloy Research Institute, Central South University, Changsha 410083, China \\ * Correspondence: victory.achun@163.com (H.J.); jgtang@csu.edu.cn (J.T.); \\ Tel.: +86-139-7554-1536 (H.J.); +86-180-7311-0262 (J.T.)
}

check for

updates

Citation: Lu, J.; Jiang, H.; Ye, L.; Sun, D.; Zhang, Y.; Zhan, X.; Li, Y.; Ma, L.; Ran, Q.; Tang, J. Effect of Aging Time on Crushing Performance of Al-0.5Mg-0.4Si Alloy for Safety Components of Automobile. Metals 2021, 11, 608. https://doi.org/ $10.3390 /$ met11040608

Academic Editor: Murat Tiryakioglu

Received: 9 March 2021

Accepted: 2 April 2021

Published: 9 April 2021

Publisher's Note: MDPI stays neutral with regard to jurisdictional claims in published maps and institutional affiliations.

Copyright: (c) 2021 by the authors. Licensee MDPI, Basel, Switzerland. This article is an open access article distributed under the terms and conditions of the Creative Commons Attribution (CC BY) license (https:// creativecommons.org/licenses/by/ $4.0 /)$.

\begin{abstract}
The effect of aging time on the crushing performance of Al-0.5Mg-0.4Si alloy used for safety components of automobile was investigated by tensile test and crush test. Moreover, the microstructure of the alloy was investigated by transmission electron microscopy (TEM). The results show that the localized deformation ductility index, $\Delta A_{a b s}$, which is defined as the difference between total elongation and uniform elongation, of $\mathrm{Al}-0.5 \mathrm{Mg}-0.4 \mathrm{Si}$ alloy is $6.5 \%, 7.0 \%$ and $8.5 \%$, respectively, after being aged at $210{ }^{\circ} \mathrm{C}$ for 1,3 and $6 \mathrm{~h}$, and this tendency is the same as that of the crushing performance. The spacing of grain boundary precipitates (GBPs) from TEM results are found to be $94.9,193.6$ and $408.2 \mathrm{~nm}$ after being aged at $210^{\circ} \mathrm{C}$ for 1,3 and $6 \mathrm{~h}$, respectively, and this tendency is same to that of $\Delta A_{a b s}$. A mechanism about the relation between the spacing of GBPs and the ductility index $\Delta A_{a b s}$ has been proposed based on localized deformation around GBPs. With the increase of GBPs spacing, the $\Delta A_{a b s}$ increases, and the crushing performance is improved.
\end{abstract}

Keywords: Al-Mg-Si alloy; aging time; crushing performance; grain boundary precipitate; localized deformation

\section{Introduction}

With the development of automobile lightweight, more attention has been focused on safety problems related to this. When a car is involved in a frontal collision in a traffic accident, the bumper system, consisting of the bumper beam, energy absorbing box and front rail, absorbs about $50 \%$ of the total kinetic energy [1,2]. The energy absorbing box is an important component that connects the bumper beam to the front rail, and absorbs energy through its deformation, accounting for about $15 \%$ of the total absorbed energy $[1,2]$. Al-Mg-Si alloy is widely used as automotive lightweight material due to its low density, medium strength, corrosion resistance and good formability [3,4]. Meanwhile, it is widely used in automotive energy absorbing box due to its greater mass-to-energy absorption than steel [5].

The crushing performance is very important to the energy absorbing box, which is used to evaluate the ability to absorb energy. In recent years, many studies have attempted to enhance the safety of automobiles by improving the crushing performance of the energy absorption box. Tang et al. [6] reported that the energy-absorption efficiency of a rectangular tube is about $70 \%$ of that of a circular tube. Some specific corrugations in circular tubes, such as sinusoidal corrugation [7], are used to reduce the deformation heterogeneity and improve the energy-absorption performance [8]. However, there were various difficulties 
when assembling the circular components with the others in the automobile structures. Kim et al. [9] suggested that the folding shape tends to become symmetric in a compressive deformation, as the thickness/width ratio of a rectangular aluminum tube is large and the energy absorption efficiency is accordingly improved. Zhang et al. [10] reported that a multi-cell metal tube is more efficient than a single-cell tube. Wang et al. [11] found that the second-order hybrid Koch absorbers outperform most of the multi-cell structures with the same mass. Saharnaz et al. [12] found that the crushing performance of holed tube is better than that of the normal and grooved tube for both steel and aluminum component. Furthermore, the energy absorbed per kilogram of the aluminum tube was relatively higher than that of the steel tube.

All of the aforementioned studies are about the effect of shape and structure of the energy absorbing box tube on energy-absorbing performance, and there are also some researches about the effect of materials. Bambach [13] and Han [14] found that the energy-absorption capacity of metal/carbon-fiber-reinforced polymer (CFRP) tubes was better than that of either metal or CFRP tubes. However, the anisotropy of composite materials brings difficulties to the design and analysis of energy absorbers [15]. Meanwhile, composite materials are difficult to recycle, and the manufacturing cost is relatively higher than metals, which limits its use in the automotive [15]. Laura et al. [16] found that the combination of strain hardening and local heat treatment can be used to improve the crushing performance of the energy-absorbing box, compared to a globally heat-treated one. Hitoshi et al. [17] suggested that the thickness of surface recrystallization layer should be less than $500 \mathrm{~nm}$, and the thickness of the fibrous structure should be more than $50 \%$ of the entire thickness ( 1 to $5 \mathrm{~mm}$ ) for the materials used in the frame structure of the automobile. Maezoli et al. [18] suggested that an overaged temper such as T7 would be appropriate for an aluminum alloy used for components requiring a high capacity for absorbing kinetic energy by plastic deformation. Henn et al. $[19,20]$ proposed some indices from tensile test to evaluate the crushing performance. The reliability of the method based on fracture surface measurement at tensile test was proved according to Parson [21].

Maezoli and Tundal et al. mentioned that the $210{ }^{\circ} \mathrm{C} \mathrm{T7}$ overaged temper would be favorable to the crushing performance for the material used for an energy absorbing box; however, they did not reveal the mechanism [18,22]. In the present study, the effect of aging time on the ductility indices derived from the tensile test $[19,20]$ and crushing performance of Al-0.5Mg-0.4Si alloy used energy absorbing box was investigated. Optical microscopy $(\mathrm{OM})$ and transmission electron microscope (TEM) were used to investigate the effect of aging time on grain size and precipitates, and to reveal corresponding mechanism about the effect of microstructure on the crushing performance of the investigated alloy.

\section{Experimental}

The chemical composition of the Al-0.5Mg-0.4Si alloy is shown in Table 1 . The as-cast ingot was homogenized and extruded into a single-cell tube, according to the commercial production process based on Saha P.K.'s research [23] of such an alloy. The tubes were on-line water-quenched at $530{ }^{\circ} \mathrm{C}$ and were subsequent artificially aged at $210{ }^{\circ} \mathrm{C}$, based on previous researches $[18,22]$, for 1,3 and $6 \mathrm{~h}$, selected from the age-hardening curve, which is discussed subsequently.

Table 1. Chemical composition of the investigated Al-Mg-Si alloy (wt.\%).

\begin{tabular}{ccccccc}
\hline Elements & $\mathbf{M g}$ & $\mathbf{S i}$ & $\mathbf{F e}$ & $\mathbf{T i}$ & $\mathbf{M n}$ & $\mathbf{A l}$ \\
\hline Content & 0.52 & 0.42 & 0.14 & 0.01 & 0.01 & Bal. \\
\hline
\end{tabular}

The specimens with dimension $20 \mathrm{~mm} \times 20 \mathrm{~mm} \times 2 \mathrm{~mm}$ used for age-hardening curve were cut from the tubes and ground on the SiC-paper for hardness measurement. Hardness was measured by using a Wilson VH1202 Vickers (ITW Test \& Measurement, Shanghai, China) hardness tester with a load of $4.9 \mathrm{~N}$ and indentation time of $10 \mathrm{~s}$. Five hardness indentations were performed to obtain an average value for each specimen. 
Figure 1 shows the age-hardening curve of the specimen aged at $210^{\circ} \mathrm{C}$. It can be seen in the curve that the hardness of the specimen reached peak value rapidly within $1 \mathrm{~h}$, and then the hardness decreased slowly. When the aging time reached $3 \mathrm{~h}$, the specimen was overaged already. According to previous researches, $\mathrm{T} 7$ overaged temper is favorable to the crushing performance $[18,22]$. To obtain specimens with some differences in crushing performance, the artificially aging times of the specimens were selected as 1,3 and $6 \mathrm{~h}$, and the specimens were named $\mathrm{A} 1, \mathrm{~A} 3$ and $\mathrm{A} 6$, respectively.

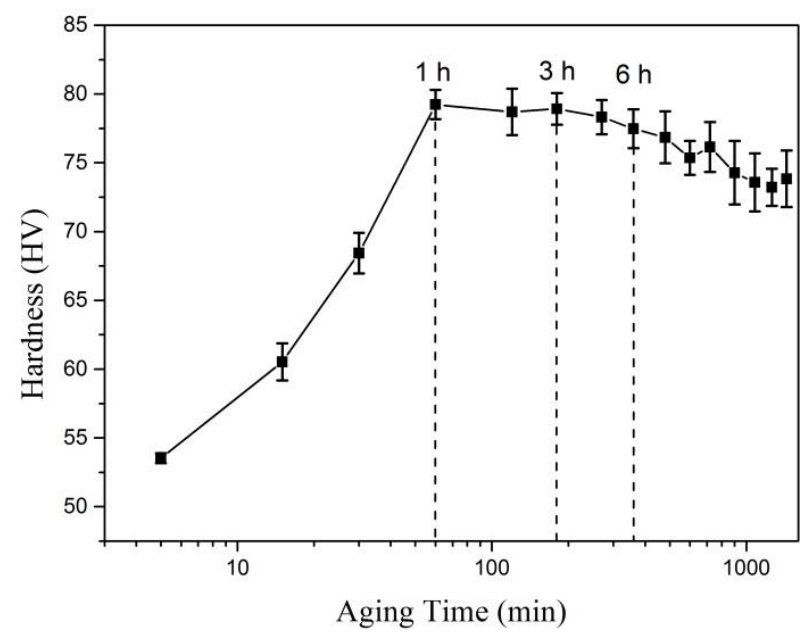

Figure 1. Evolution of hardness of the specimens artificially aged at $210{ }^{\circ} \mathrm{C}$.

The crushing performance was carried out according to BMW Material SpecificationWS 02002 and was tested with MTS E64.106 electro-hydraulic servo universal test machine (MTS SYSTEMS (CHINA) CO., LTD., Shenzhen, China, $1000 \mathrm{kN}$ ). The specimens were compressed along the extrusion direction, from 300 to $100 \mathrm{~mm}$, at a speed of $100 \mathrm{~mm} / \mathrm{min}$. The cracks developed during crushing test were used to evaluate crushing performance, and it can be accepted when the length of a crack is less than $10 \mathrm{~mm}$, and even preferentially less than $5 \mathrm{~mm}$ [24]. In order to investigate the crushing performance quantitatively, the degree of crushing performance was assessed qualitatively, using a grading scale from 1 to 9 , with a grade of 1 being the worst crushing performance and a grade of 9 representing the best crushing performance. Table 2 summarizes a crushing performance rating system, which is the modified version of the one proposed in research [21].

Table 2. Crushing performance rating system.

\begin{tabular}{cc}
\hline Grade & Description \\
\hline 1 & Entire box fragmentation \\
2 & Deep transverse cracks and fragmentation and severe corner cracking \\
3 & Internal and external transverse cracks and severe corner cracking \\
4 & Internal shallow transverse crack and multiple deep corner cracks \\
5 & Multiple deep corner cracks on the folds \\
6 & Few deeper corner cracks on the folds \\
7 & Few small corner cracks on the folds \\
8 & One small corner crack on the folds \\
9 & No cracks on the surface \\
\hline
\end{tabular}

The tensile test was carried out on the MTS810 computer-controlled test machine (MTS Systems Corporation, Eden Prairie, USA) with a loading speed of $2 \mathrm{~mm} / \mathrm{min}$, at room temperature, according to GB/T 228-2010. The "dog-bone" type tensile test specimens with a gauge length of $25 \mathrm{~mm}$ and cross-section of $2.3 \times 10 \mathrm{~mm}^{2}$ were cut with stretching direction along the extrusion direction. The tensile properties were the mean value of three repeated specimens. 
The metallographic grain structure of the extruded tube was examined in a Leica DM2700M optical microscope (Leica Microsystems Cms GmbH, Wetzlar, Germany) with polarized light. The specimens used for optical microscopy (OM) examination were mechanically ground with silicon carbide $(\mathrm{SiC})$ papers up to grade 1500, polished with $2.5 \mu \mathrm{m}$ diamond pastes and then anodized for 30-45 s with a solution of $190 \mathrm{~mL}$ distilled water and $10 \mathrm{~mL} \mathrm{HBF}_{4}$, at a voltage of $25 \mathrm{~V}$.

The precipitates of specimens were investigated by Titan G2 60-300 and JEM-2100F (JEOL LTD., Akishima, Tokyo, Japan) operated at an acceleration voltage of $200 \mathrm{kV}$. Foils for TEM observation were mechanically ground to a thickness of about $80 \mu \mathrm{m}$ and punched into discs with a diameter of $3 \mathrm{~mm}$. The discs were further etched by twin-jet polishing with $30 \%$ nitric acid in methanol, operating at temperature, between -30 and $-20{ }^{\circ} \mathrm{C}$, at a voltage of $16 \mathrm{~V}$.

\section{Results}

\subsection{Crushing Test}

The specimens after the crushing test are shown in Figure 2. Folding to various degrees is found in three investigated specimens; nevertheless, the folds of the A3 and A6 specimens are more symmetric than those of the A1 specimen. There are some cracks marked by red rectangles in the A1 and A3 specimens, as shown in Figure 2. The statistical data about cracks and the crushing performance grade of specimens are listed in Table 3. For the A1 specimen, a penetrated crack exceeding $30 \mathrm{~mm}$ is found in the folds, and two small cracks are found in the backside, resulting in a grade 6 crushing performance. For the A3 specimen, however, only two small cracks, 10 and $10-20 \mathrm{~mm}$, respectively, are found at the corner of the fold, resulting in a grade 7 crushing performance. Compared with the other two specimens, no visible cracks are found from A6 specimen after crushing test, indicating a grade 9 crushing performance. This means that the crushing performance of the A6 specimen is the best among the three specimens, followed by the A3 specimen, and the worst one is the A1 specimen.
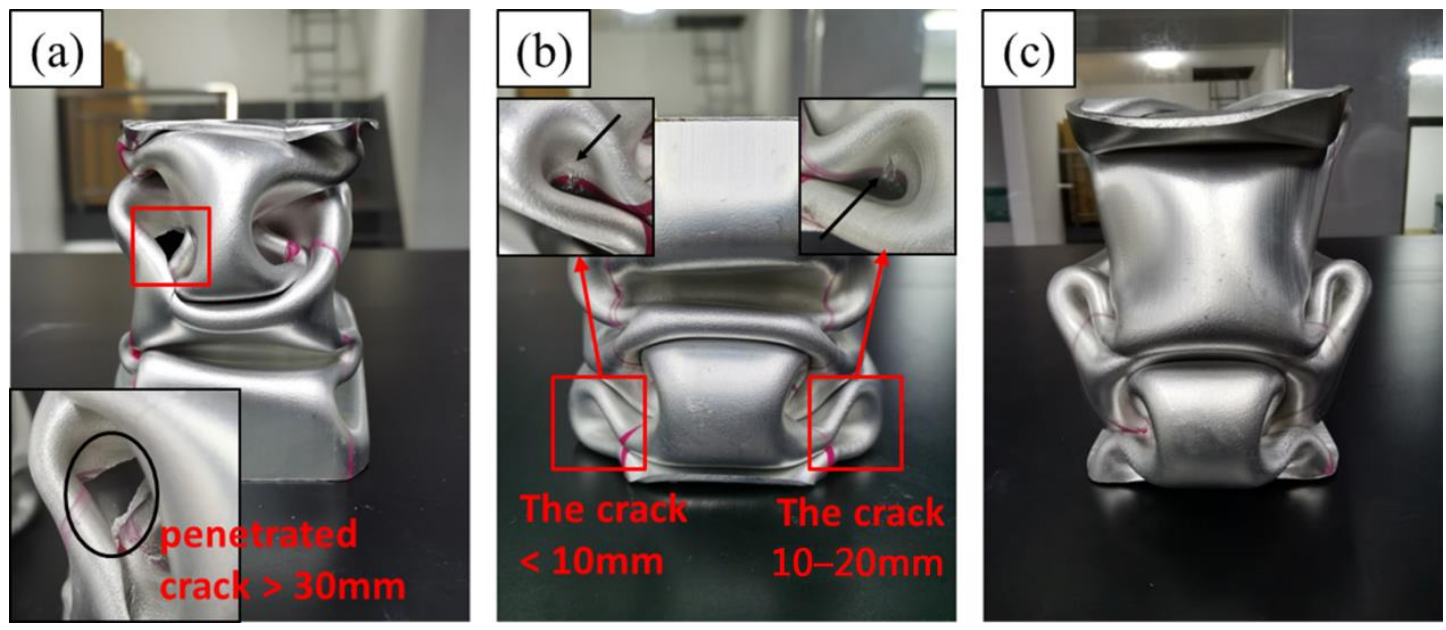

Figure 2. Folds and cracks formed in specimens after crushing test: (a) A1, (b) A3 and (c) A6.

Table 3. Number of cracks in specimens after crushing test and grade of crushing performance.

\begin{tabular}{|c|c|c|c|c|c|}
\hline \multirow{2}{*}{ Specimens } & \multicolumn{4}{|c|}{ Number of Cracks } & \multirow{2}{*}{$\begin{array}{l}\text { Grade of Crushing } \\
\text { Performance }\end{array}$} \\
\hline & Length $<10 \mathrm{~mm}$ & Length $=10-20 \mathrm{~mm}$ & Length $=20-30 \mathrm{~mm}$ & Length $>30 \mathrm{~mm}$ & \\
\hline A1 & 2 & 0 & 0 & 1 & 6 \\
\hline A3 & 1 & 1 & 0 & 0 & 7 \\
\hline A6 & 0 & 0 & 0 & 0 & 9 \\
\hline
\end{tabular}




\subsection{Tensile Test}

The tensile-test results of three specimens are listed in Table 4. The yield strength (YS) and ultimate tensile strength (UTS) of the specimen aged for $1 \mathrm{~h}$ are 202.4 and $226.1 \mathrm{MPa}$ respectively, and the total elongation is $13.8 \%$; with the aging time increased to $3 \mathrm{~h}$, the YS and UTS decrease 16.1 and $12.0 \mathrm{MPa}$, respectively, and the total elongation increases slightly; by further increasing the aging time to $6 \mathrm{~h}$, the YS and UTS decrease 12.0 and 10.7 MPa, respectively, and the total elongation increases obviously to $15.0 \%$. The above results reveal that both the YS and UTS of the specimens decrease significantly with increasing aging time, while the total elongation showed the opposite trend, increasing with the increase of aging time.

Table 4. Mechanical properties of three specimens.

\begin{tabular}{ccccc}
\hline Specimens & YS/MPa & UTS/MPa & $A / \%$ & $A_{g} / \%$ \\
\hline A1 & $202.4 \pm 4.2$ & $226.1 \pm 0.2$ & $13.7 \pm 0.4$ & $7.2 \pm 0.1$ \\
A3 & $186.3 \pm 1.8$ & $214.1 \pm 1.3$ & $13.9 \pm 1.4$ & $6.9 \pm 0.2$ \\
A6 & $174.3 \pm 1.3$ & $203.4 \pm 0.8$ & $15.0 \pm 0.3$ & $6.5 \pm 0.1$ \\
\hline
\end{tabular}

YS, yield strength; UTS, ultimate tensile strength.

According to Henn et al. [20], conventional tensile-test-analysis results are limited in investigating the crushing performance potential. Hence, based on tensile test data, different ductility indices, i.e., $\Delta A_{a b s}, \Delta A_{s p e z}$ and TFS, were proposed to evaluate the crushing performance potential.

$$
\begin{aligned}
& \Delta A_{a b s}=A-A_{g} \\
& \Delta A_{\text {spez }}=\frac{\Delta A_{a b s}}{A_{g}} \\
& T F S=\ln \left(\frac{S_{0}}{S_{f}}\right)
\end{aligned}
$$

where $A$ is the total elongation, $A_{g}$ is the uniform elongation (the elongation before necking), $S_{0}$ is the original cross-sectional area of the tensile test specimen and $S_{f}$ is the minimum cross-sectional area after fracture. Some of the parameters are listed in Table 4. According to these ductility indices, the larger the values of the parameters obtained, the better the crushing performance.

In the tensile test, the total elongation of the specimens increased with the increase of aging time, especially when the aging time was increased to $6 \mathrm{~h}$, as shown in Table 4 . While the change of the uniform elongation $\left(A_{g}\right)$ is considerably small to be neglected, the difference of total elongation is essentially the difference of $\Delta A_{a b s}$, which is defined as the elongation after necking, i.e., the localized deformation ductility index, as shown in Figure 3a. Concisely, Equations (1)-(3) can be used to calculate the $\Delta A_{a b s}, \Delta A_{\text {spez }}$ and TFS of the specimens, respectively. It can be found from Figure $3 \mathrm{~b}$ that the $\Delta A_{a b s}, \Delta A_{\text {spez }}$ and TFS increase with the aging time. Specifically, the $\Delta A_{a b s}$ of the A1, A3 and A6 specimens is $6.5 \%, 7.0 \%$ and $8.5 \%$, respectively. The $\Delta A_{\text {spez }}$ of the $\mathrm{A} 1, \mathrm{~A} 3$ and $\mathrm{A} 6$ specimens is $0.9,1.0$ and 1.3, respectively, and the TFS of the A1, $\mathrm{A} 3$ and $\mathrm{A} 6$ specimens is $0.78,0.83$ and 1.16, respectively. The ductility indices $\Delta A_{a b s}, \Delta A_{\text {spez }}$ and TFS of the A6 specimen are the highest, followed by the A3 specimen, and the A1 specimen is the lowest one, which is consistent with the results of the crushing test (i.e., crushing performance grade $\mathrm{A} 1<\mathrm{A} 3<\mathrm{A} 6$ ). It is worth noting that the evolution tendency of $\Delta A_{a b s}$ is supposed to be the most suitable one for the grade of crushing performance among the three parameters, as illustrated in Figure $3 b$. 

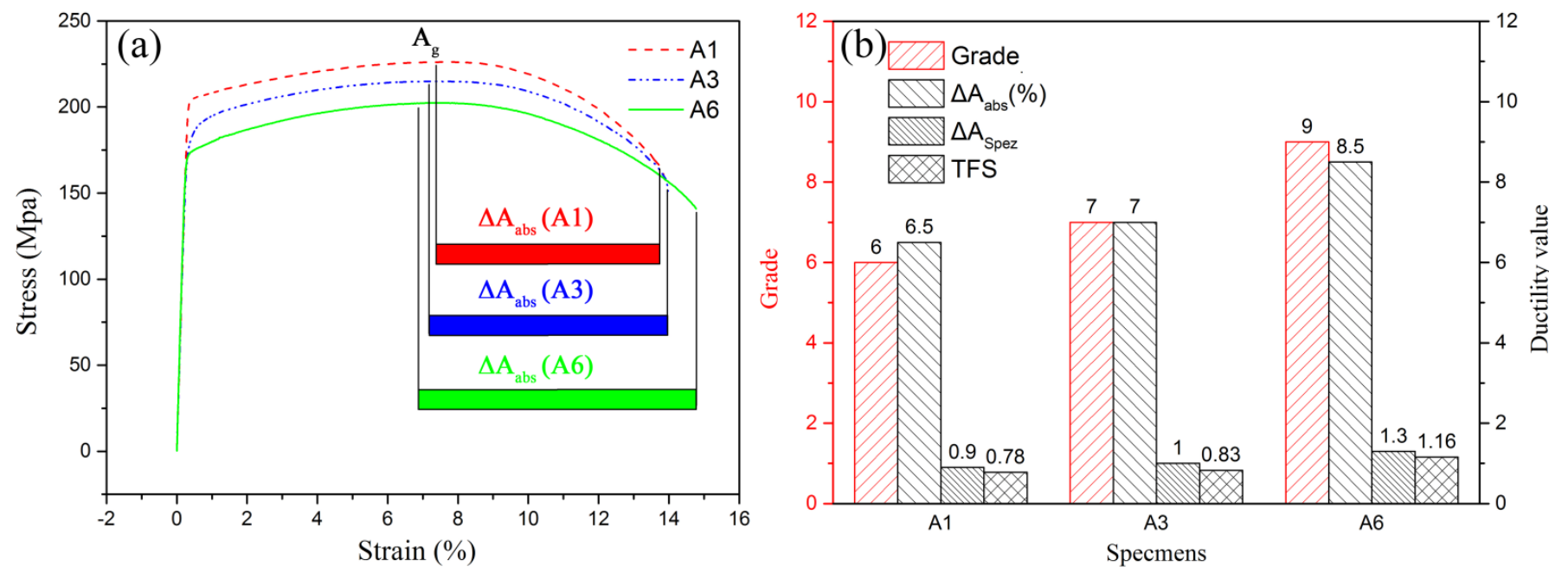

Figure 3. Information about (a) stress-strain curve in tensile test and (b) relationship between crushing grade and ductility indices.

\subsection{Metallographic}

The metallographic of three specimens is shown in Figure 4. Equiaxed grains could be found in three specimens, so it is obvious that they are completely recrystallized. According to statistics, the average grain size of the A1, A3 and A6 specimens is $104.9 \pm 9.7 \mu \mathrm{m}$, $107.5 \pm 9.6 \mu \mathrm{m}$ and $105.9 \pm 9.0 \mu \mathrm{m}$, respectively. The grain-size differences among the three specimens are not significant, indicating that the effect of aging time on the grain size can be neglected.
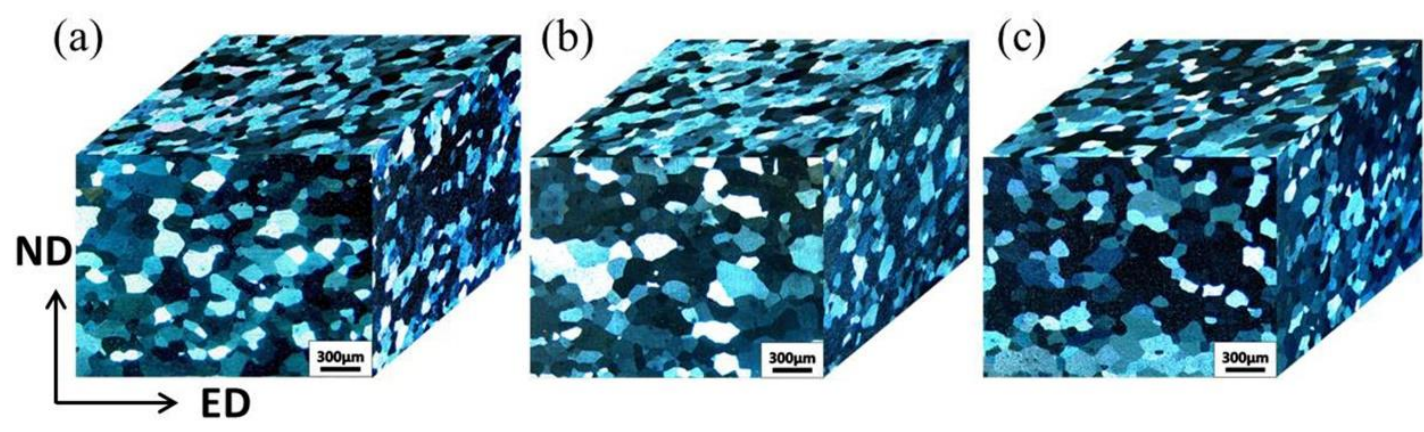

Figure 4. Three-dimensional metallographic of specimens: (a) A1, (b) A3 and (c) A6.

\subsection{TEM Results}

The TEM images and the selected area diffraction patterns (SADPs) of the three specimens are shown in Figure 5. The TEM images were acquired along $<001>$ Al zone axes. A large number of uniformly distributed dot-like and needle-like precipitates are found within grains of the three specimens. The cross-shaped diffraction patterns near to that of $(110)_{\mathrm{Al}}$ were found in the SADPs, as marked in Figure 5. Based on the age-hardening curve (Figure 1) and previous research [25], the cross-shaped diffraction patterns in the specimens likely indicated that the precipitates were $\beta^{\prime}$ and $\beta^{\prime \prime}$ phases for the A1 specimen, and as for the $\mathrm{A} 3$ and $\mathrm{A} 6$ specimens, the precipitates were $\beta^{\prime}$ phase because the $\mathrm{A} 3$ and A6 specimens were overaged. The average diameters of the precipitates in the A1, A3 and A6 specimens are $5.3 \pm 1.5 \mathrm{~nm}, 5.9 \pm 1.9 \mathrm{~nm}$ and $6.7 \pm 2.1 \mathrm{~nm}$, respectively; the average lengths of the precipitates in the A1, A3 and A6 specimens are $41.3 \pm 34.4 \mathrm{~nm}$, $116.4 \pm 82.3 \mathrm{~nm}$ and $125.6 \pm 97.3 \mathrm{~nm}$, respectively; and the average number densities of the A1, A3, A6 specimens are $278.1 \pm 12.6 \mu \mathrm{m}^{-2}, 88.2 \pm 3.2 \mu \mathrm{m}^{-2}$ and $80.1 \pm 3.0 \mu \mathrm{m}^{-2}$, respectively, as shown in Table 5. In addition, the diameter and length distribution trends of precipitates are displayed in Figure 6. It is obvious that, as the aging time increases, both 
the diameter and length of the precipitates increase. It is also worth noting that the change of the average precipitates length and the number density from 3 to $6 \mathrm{~h}$ is much smaller than that from 1 to $3 \mathrm{~h}$.
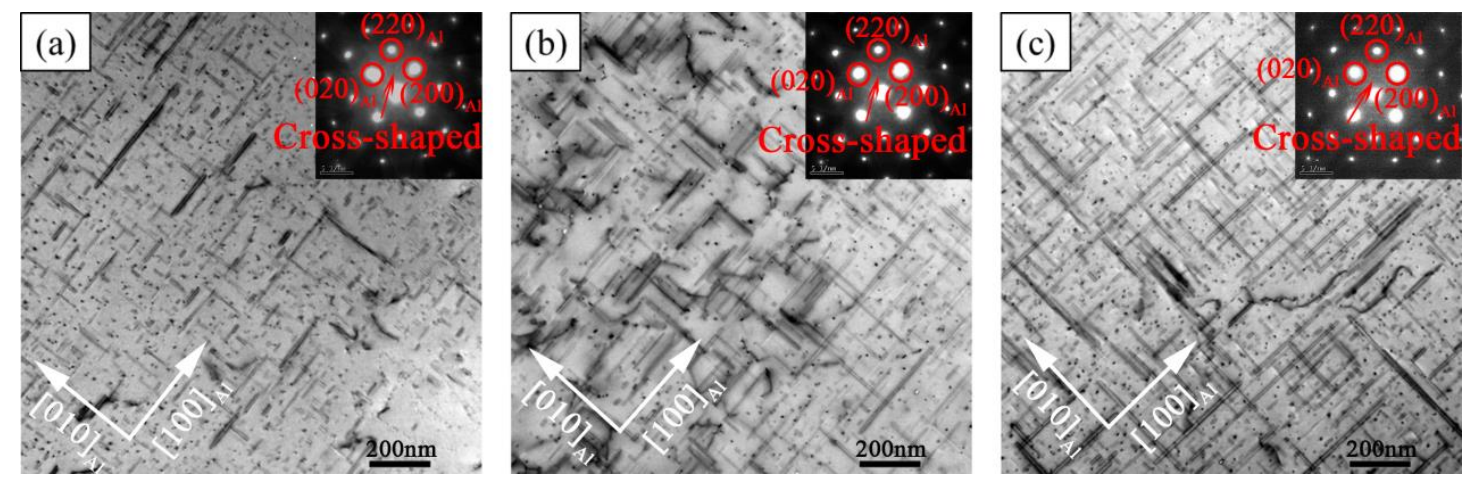

Figure 5. Transmission electron microscopy (TEM) images of the three investigated specimens: (a) A1, (b) A3 and (c) A6.

Table 5. Average diameter, length and number density of the precipitates within the grains.

\begin{tabular}{cccc}
\hline Specimens & $\begin{array}{c}\text { Average Diameter of the } \\
\text { Precipitates }\left(\mathbf{C I}^{\mathbf{1}}\right) / \mathbf{n m}\end{array}$ & $\begin{array}{c}\text { Average Length of the } \\
\text { Precipitates }(\mathbf{C I}) / \mathbf{n m}\end{array}$ & $\begin{array}{c}\text { Average Number Density } \\
(\mathbf{C I}) / \boldsymbol{\mu m} \mathbf{m}^{-2}\end{array}$ \\
\hline A1 & $5.3 \pm 1.5([5.2,5.4])$ & $41.3 \pm 34.4([39.7,42.9])$ & $278.1 \pm 12.6([277.1,279.1])$ \\
A3 & $5.9 \pm 1.9([5.8,6.0])$ & $116.4 \pm 82.3([110.8,122.0])$ & $88.2 \pm 3.2([88.0,88.4])$ \\
A6 & $6.7 \pm 2.1([6.5,6.9])$ & $125.6 \pm 97.3([121.5,129.7])$ & $80.1 \pm 3.0([79.8,80.4])$ \\
\hline
\end{tabular}

${ }^{1}$ CI: confidence intervals. The confidence level is $95 \%$.
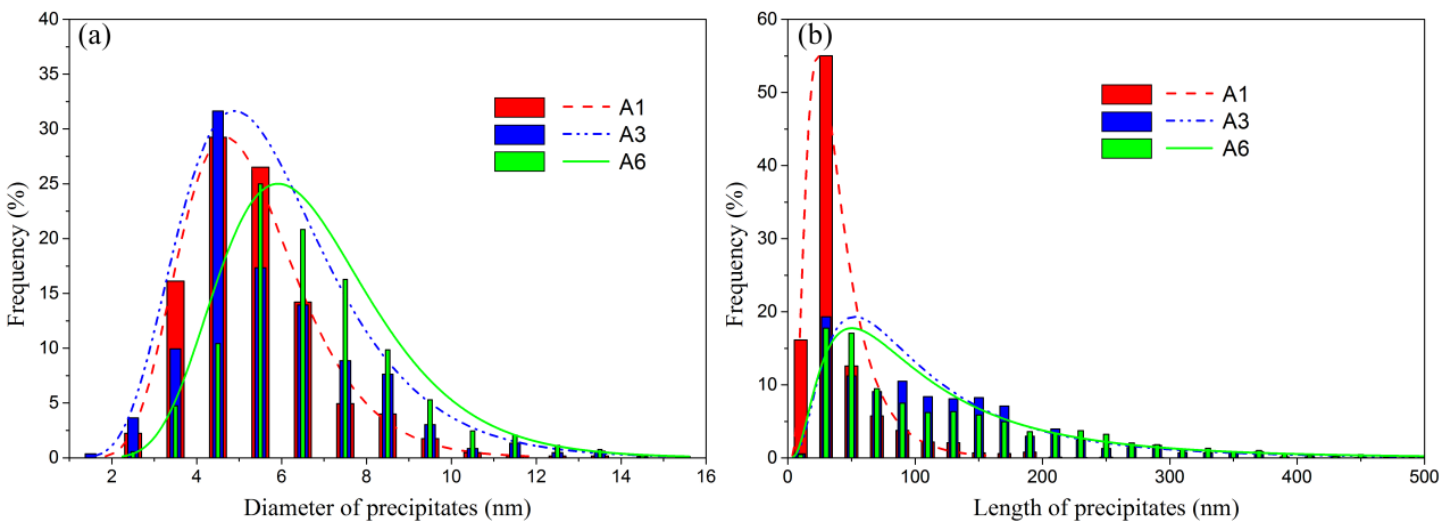

Figure 6. The distribution of (a) diameter and (b) length of precipitates within grains of the investigated specimens.

Figure 7 is the TEM bright-field images around the grain boundaries of the three investigated specimens. It can be seen from the figure that some irregular particles that are much larger than the precipitates within grains are precipitated at the grain boundary, i.e., large grain boundary precipitates (GBPs) are found at the grain boundary. STEM-EDS results shown in Figure 8 reveal that the density of Si inside the GBP is obviously larger than the matrix. Therefore, the GBPs are a type of Si-rich particle and are supposed to be monatomic silicon. It can be found from Figure 7 that the spacing of such GBPs increases with the aging time. The statistical results of such GBPs are listed in Table 6. The spacing of GBPs in the A1 specimen that was aged for $1 \mathrm{~h}$ is $94.9 \pm 60.4 \mathrm{~nm}$; that of the A3 specimen that was aged for $3 \mathrm{~h}$ is increased to $193.0 \pm 125.0 \mathrm{~nm}$, and that of the A6 specimen that was aged for $6 \mathrm{~h}$ is further increased to $408.2 \pm 201.4 \mathrm{~nm}$. The average diameters of GBPs in the A1, A3, and A6 specimens, i.e., $55.4 \pm 15.2 \mathrm{~nm}, 61.6 \pm 11.0 \mathrm{~nm}$ and $70.4 \pm 14.3 \mathrm{~nm}$, respectively, increase slightly with the increasing of aging time. However, there exists no specific regularity on precipitate-free zones (PFZs), and the width of PFZs in A1, A3 and A6 specimens is $266.9 \pm 39.2 \mathrm{~nm}, 259.2 \pm 38.7 \mathrm{~nm}$ and $310.5 \pm 27.7 \mathrm{~nm}$, respectively. All 
values about the precipitates within grains and GBPs were measured with Image-pro-plus software, and at least three graphs were selected for each datum.
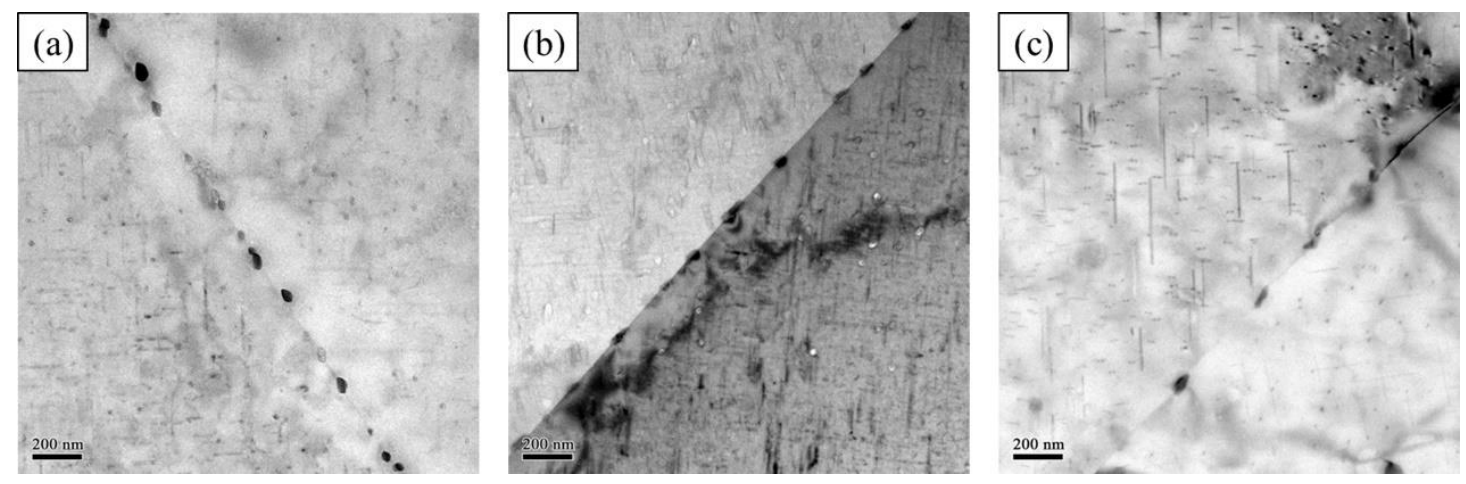

Figure 7. Transmission electron microscopy (TEM) images of grain-boundary precipitates in the three investigated specimens: (a) A1, (b) A3 and (c) A6.
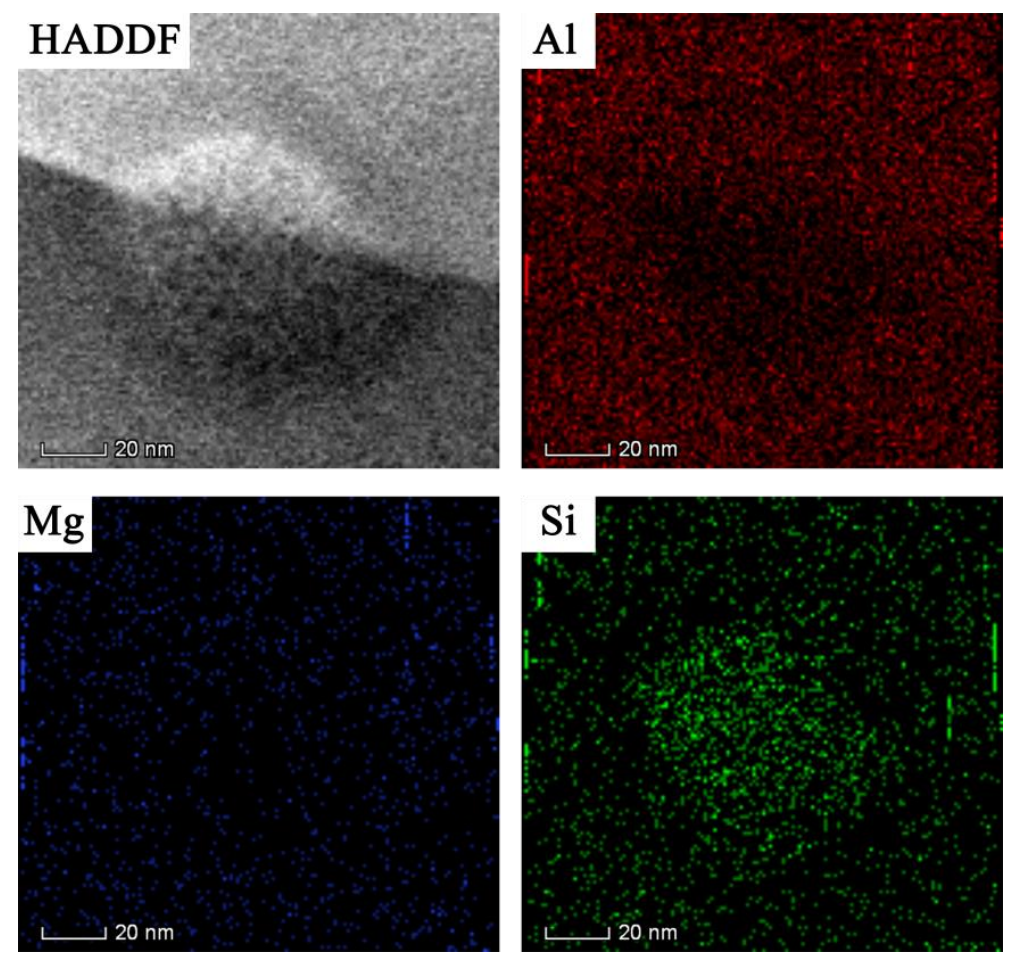

Figure 8. STEM-EDS result of grain boundary precipitates (GBPs).

Table 6. Average spacing and diameter of GBPs.

\begin{tabular}{ccc}
\hline Specimens & Spacing of GBPs $\left(\mathbf{C I}^{\mathbf{1}}\right) / \mathbf{n m}$ & Diameter of GBPs $(\mathbf{C I}) / \mathbf{n m}$ \\
\hline A1 & $94.9 \pm 60.4([74.9,114.9])$ & $55.4 \pm 15.2([50.4,60.4])$ \\
A3 & $193.0 \pm 125.0([154.3,231.7])$ & $61.6 \pm 11.0([58.2,65.0])$ \\
A6 & $408.2 \pm 201.4([341.5,474.9])$ & $70.4 \pm 14.3([65.7,75.1])$ \\
\hline
\end{tabular}

${ }^{1}$ CI: confidence intervals. The confidence level is $95 \%$.

\section{Discussion}

As shown in Table 4, both YS and UTS of the investigated alloy decrease with the increasing aging time. Precipitation strengthening is likely a good explanation for the change of YS and UTS. Precipitation strengthening and grain refinement strengthening are the primary strengthening mechanisms of aluminum alloys. According to the metallographic results shown in Section 3.3, the effect of aging time on grain size and grain shape is so 
small that it can be neglected. Thus, the differences of the strengthening among the three specimens are primarily ascribed to the contribution of the precipitation strengthening. According to Figure 1, both the A3 specimen and A6 specimen are overaged, and the Orowan mechanism is supposed to be the main dislocation and precipitates interaction mechanism. From Table 5, we see that both the diameter and length of the precipitates increase with increasing aging time, while the number density decreases. The precipitates of the A1 specimen are smaller and denser than those of the A3 and A6 specimens; as for the $\mathrm{A} 3$ specimen, the precipitates are smaller and denser than those of the A6 specimen, leading to the highest YS and UTS of the A1 specimen, followed by the A3 specimen; and the A6 specimen is the lowest.

The above discussion is about the relation between microstructure and strength, but the relation between microstructure and crushing performance has rarely been investigated. According to Figure 3, the evolution tendency of the crushing performance is almost consistent with that of the localized deformation ductility index, $\Delta A_{a b s}$. To some extent, the $\Delta A_{a b s}$ could be used to evaluate the crushing performance of different specimens, which is consistent with previous researches $[19,20]$.

As is known, at the same aging temperature, the aging time mainly affects the precipitates in the grains and the GBPs. Therefore, in order to reveal which one of these two factors (precipitates within the grains and GBPs) is the most important one affecting $\Delta A_{a b s}$ and crushing performance, the evolutions of the $\Delta A_{a b s}$, spacing and diameter of GBPs, as well as of the length and number density of precipitates within grains during aging, are plotted together in Figure 9. Figure 9a demonstrates that the spacing of GBPs shows a similar tendency to that of $\Delta A_{a b s}$. On the other hand, however, the change of diameters is not very obvious, thus implying that its effect on $\Delta A_{a b s}$ is insignificant. Furthermore, the evolution of the length and density of precipitates within the grains differs from that of the $\Delta A_{a b s}$, as shown in Figure $9 \mathrm{~b}$. Hence, one can expect that the changes of precipitates within the grains are not properly reflecting the changes in $\Delta A_{a b s}$. Consequently, we can conclude that the spacing of GBPs is the most important factor affecting the $\Delta A_{a b s}$ and crushing performance of the investigated alloy.
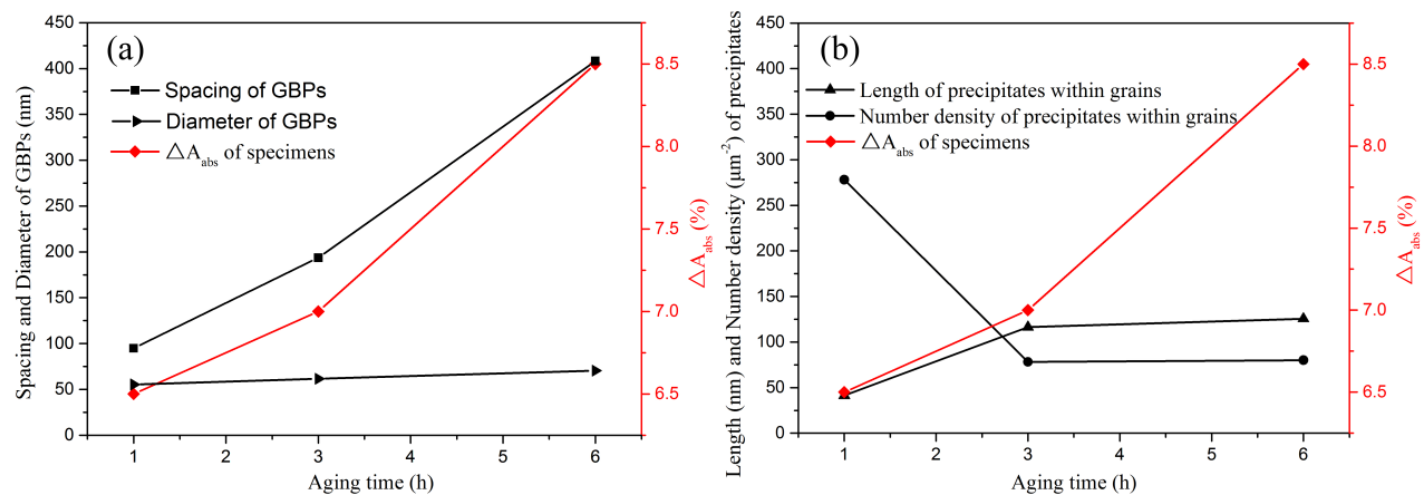

Figure 9. Evolution of ductility index, $\Delta A_{a b s}$, with (a) spacing and diameter of GBPs and (b) length and number density of precipitates within grains.

Based on the above assumption, a microcrack-formation mechanism about the relation between GBPs and $\triangle A_{a b s}$ is proposed, as shown in Figure 10. As is known, the GBPs are incoherent with the matrix, so the presence of the GBPs is equivalent to the formation of voids at the grain boundaries. The voids will be elongated when the stress around the voids is large enough. Such micro-scale localized deformation around these elongated voids would quickly develop into macro-scale deformation localization, i.e., necking. The microcracks will be generated on the grain boundary when the elongated voids make contact with each other. Such microcracks would quickly develop into macrocracks, which lead to a rapid decline of stress, i.e., failure. It is clear that the shorter the spacing between the GBPs is, the easier the formation of microcracks is, i.e., the smaller average macro-scale 
localized deformation strain $\left(\Delta A_{a b s}\right)$ after necking is. It can be guessed that when there are no GBPs, or the fraction of high angle grain boundaries in an alloy is very small, the crushing performance will be improved. This is also in line with the research of Parson [21]. The crushing performance of alloys with more fiber grains is better than alloys with more recrystallization. The incoherent interface between GBPs and the matrix and shorter GBPs spacing would accelerate the localization of deformation and deteriorate $\Delta A_{a b s}$ and crushing grade. Therefore, the GBPs spacing of the Al-Mg-Si alloy with high fraction of high-angle grain boundaries should be large enough to ensure a high crushing performance.

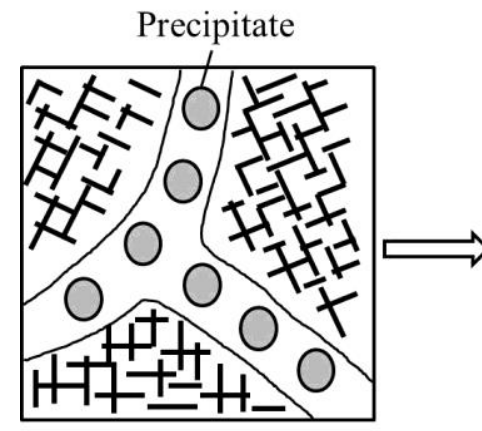

Incoherent grain boundary precipitate

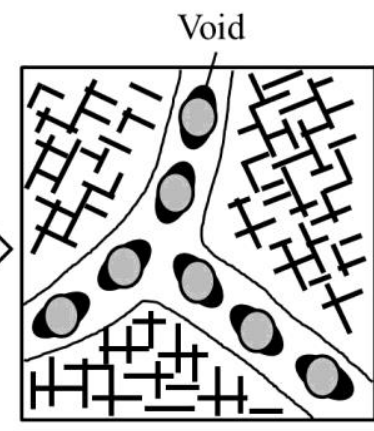

Elongation of voids

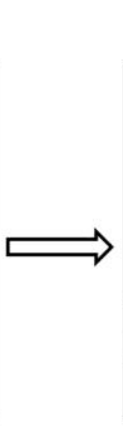

Coalesce of elongated voids to form cracks

Figure 10. Schematic diagram about the effect of GBPs on microcrack formation.

As shown in Figure 7 and Table 6, the GBPs spacing can be increased by increasing aging time; hence, the $\Delta A_{a b s}$ and crushing grade increase with aging time, as is shown in Figure 3. However, the size of main strengthening precipitates within the grains would also increase with the increase of aging time, and therefore a too-long aging time is not suitable because of the decreased strength. It can be supposed that the increase of crushing temperature would increase the $\Delta A_{a b s}$ and crushing grade, as increasing temperature would delay the deformation localization, but increasing the strain rate would accelerate deformation localization.

\section{Conclusions}

1. The crushing performance of the $\mathrm{Al}-0.5 \mathrm{Mg}-0.4 \mathrm{Si}$ alloy is strongly related to the $\Delta A_{a b s}$. The $\Delta A_{a b s}$ of the three specimens aged at $210{ }^{\circ} \mathrm{C}$ for 1,3 and $6 \mathrm{~h}$ is $6.5 \%, 7.0 \%$ and $8.5 \%$, respectively, and the crushing performance increases with the increase of the $\Delta A_{a b s}$.

2. The spacing of GBPs is the reason for the effect of aging treatment on the crushing performance of the Al-0.5Mg-0.4Si alloy. The spacing of GBPs increases with the increase of aging time. The average spacing of GBPs in the specimens aged at $210{ }^{\circ} \mathrm{C}$ for 1,3 and $6 \mathrm{~h}$ is $94.9,193.6$ and $408.2 \mathrm{~nm}$, respectively.

3. A microstructure model for recrystallized Al-Mg-Si alloy with high crushing performance is proposed based on nucleation of microcracks from GBPs. The increase of the spacing of GBPs increases the resistance of microcrack formation and thus the $\Delta A_{a b s}$ of the specimen, and further leads to an improvement of the crushing performance.

Author Contributions: Conceptualization, J.T.; data curation, J.L. and Y.L.; methodology, J.L., Y.Z. and J.T.; project administration, H.J. and J.T.; resources, H.J., L.Y., D.S. and Q.R.; software, X.Z. and L.M.; supervision, L.Y. and J.T.; validation, H.J.; writing—original draft, J.L.; writing-review and editing, J.T. All authors have read and agreed to the published version of the manuscript.

Funding: The authors would like to appreciate the financial supports from the Natural Science Foundation Program (No. 51474240) and Science and Technology on High Strength Structural Materials Laboratory Program (6142912180104).

Institutional Review Board Statement: Not applicable. 
Informed Consent Statement: Not applicable.

Data Availability Statement: Not applicable.

Conflicts of Interest: The authors declare no conflict of interest.

\section{References}

1. Han, M.S.; Min, B.S.; Cho, J.U. Fracture properties of aluminum foam crash box. Int. J. Automot. Technol. 2014, 15, 945-951. [CrossRef]

2. Witteman, W.J. Improved Vehicle Crashworthiness Design by Control of the Energy Absorption for Different Collision Situations. Ph.D. Thesis, Technische Universiteit Eindhoven, Eindhoven, The Netherlands, 1999.

3. Miller, W.S.; Zhuang, L.; Bottema, J.; Wittebrood, A.; De Smet, P.; Haszler, A.; Vieregge, A.J.M.S. Recent development in aluminum alloys for the automotive industry. Mater. Sci. Eng. A 2000, 280, 37-49. [CrossRef]

4. Hirsch, J. Recent development in aluminium for automotive applications. Trans. Nonferrous Met. Soc. China 2014, $24,1995-2002$. [CrossRef]

5. Das, S.K.; Green, J.A.S.; Kaufman, J.G. The development of recycle-friendly automotive aluminum alloys. JOM 2007, 59, 47-51. [CrossRef]

6. Tang, Z.; Liu, S.; Zhang, Z. Analysis of energy absorption characteristics of cylindrical multi-cell columns. Thin Walled Struct. 2013, 62, 75-84. [CrossRef]

7. Wu, S.; Li, G.; Sun, G.; Wu, X.; Li, Q. Crashworthiness analysis and optimization of sinusoidal corrugation tube. Thin Walled Struct. 2016, 105, 121-134. [CrossRef]

8. Singace, A.; El-Sobky, H. Behaviour of axially crushed corrugated tubes. Int. J. Mech. Sci. 1997, 39, 249-268. [CrossRef]

9. Kim, D.-K.; Lee, S. Impact energy absorption of 6061 aluminum extruded tubes with different cross-sectional shapes. Mater. Des. 1999, 20, 41-49. [CrossRef]

10. Zhang, X.; Zhang, H. Energy absorption of multi-cell stub columns under axial compression. Thin Walled Struct. 2013, 68, 156-163. [CrossRef]

11. Wang, J.; Zhang, Y.; He, N.; Wang, C.H. Crashworthiness behavior of Koch fractal structures. Mater. Des. 2018, 144, 229-244. [CrossRef]

12. Montazeri, S.; Elyasi, M.; Moradpour, A. Investigating the energy absorption, SEA and crushing performance of holed and grooved thin-walled tubes under axial loading with different materials. Thin Walled Struct. 2018, 131, 646-653. [CrossRef]

13. Bambach, M. Axial capacity and crushing of thin-walled metal, fibre-epoxy and composite metal-fibre tubes. Thin Walled Struct. 2010, 48, 440-452. [CrossRef]

14. Han, Z.; Li, H.; Xu, X.; Wang, H.; Li, H.; Tao, J. Crushing characteristics of alumi-num/CFRP/aluminum hybrid tubes prepared by spinning forming. Compos. Struct. 2020, 249, 112511. [CrossRef]

15. Shin, K.C.; Lee, J.J.; Kim, K.H.; Song, M.C.; Huh, J.S. Axial crush and bending collapse of an aluminum/GFRP hybrid square tube and its energy absorption capability. Compos. Struct. 2002, 57, 279-287. [CrossRef]

16. Conrads, L.; Liebsch, C.; Hirt, G. Increasing the energy absorption capacity of structural components made of low alloy steel by combining strain hardening and local heat treatment. Procedia Eng. 2017, 207, 257-262. [CrossRef]

17. Kawai, H.; Yoshihara, S.; Hirano, M. Shock Absorbing Material. U.S. Patent Application 10/420,756, 6 November 2003.

18. Marzoli, M.L.; van de Langkruis, J.; Boezewinkel, J. High Strength Crash Resistant Aluminium Alloy. EP2072628B1, 18 October 2017.

19. Henn, P.; Liewald, M.; Sindel, M. Investigation on crashworthiness characterisation of 6xxx-series aluminium sheet alloys based on local ductility criteria and edge compression tests. In Proceedings of the International Deep Drawing Research Group 37th Annual Conference, Waterloo, ON, Canada, 3-7 June 2018.

20. Henn, P.; Liewald, M.; Sindel, M. Investigation on local ductility of 6xxx-aluminium sheet alloys. In Proceedings of the 36th IDDRG Conference-Materials Modelling and Testing for Sheet Metal Forming, Munich, Germany, 2-6 July 2017.

21. Parson, N.; Fourmann, J.; Beland, J.F. Aluminum Extrusions for Automotive Crash Applications; SAE Technical Paper. No. 2017-011272; SAE International: Materials Park, OH, USA, 2017.

22. Tundal, U.; Resiso, O.; Skejervold, S.R. Al-Mg-Si Aluminium Alloy with Improved Properties. U.S. Patent 9,840,761, 25 April 2013.

23. Saha, P.K. Aluminum Extrusion Technology; ASM International, Member/Customer Service Center: Materials Park, OH, USA, 2000.

24. Alexis., S.; Martin, J. High Strength Products Extruded from 6xxx Aluminium Alloys Having Excellent Crash Performance. U.S. Patent Application 15/508,243, 26 October 2017.

25. Miao, W.F.; Laughlin, D.E. Effects of $\mathrm{Cu}$ content and presaging on precipitation characteristics in aluminum alloy 6022. Metall. Mater. Trans. A 2000, 31, 361-371. [CrossRef] 